\title{
Effect of operation regime on bubble size and void fraction in a bubble column with porous sparger
}

\author{
Shahrouz Mohagheghian ${ }^{1}$, Afshin J. Ghajar ${ }^{1}$, and Brian Elbing ${ }^{1}$ \\ ${ }^{1}$ Oklahoma State University Stillwater
}

April 28, 2020

\begin{abstract}
Performance of bubble columns under transport processes is dependent on bubble size distribution and void fraction. These multiphase parameters are sensitive to the operation regime of a bubble column. The current work presents a systematic study of bubble size and void fraction in a batch bubble column within the homogeneous and heterogeneous regimes. Effect of liquid viscosity and gas superficial velocity on bubble size distribution, void fraction, and operation regime was investigated. Results showed that increasing the viscosity accelerates the regime transition. Bubble size distributions were statistically characterized using probability density function and probability plots. It was shown that bubble size distribution shifts from near-Gaussian in the homogenous regime to lognormal (in parts) in the heterogeneous regime. Dimensional reasoning was used to scale the bubble size and void fraction with respect to the operation regime.
\end{abstract}

\section{Hosted file}

Mohagheghian_2019_AIChE_sub1b.pdf available at https://authorea.com/users/303140/articles/442616effect-of-operation-regime-on-bubble-size-and-void-fraction-in-a-bubble-column-with-poroussparger 